\title{
Improving Performance of the Braking Process, and Analysis Torque-Speed Characteristics of the Induction Motor
}

\author{
Omar M. Al-Barbarawi \\ Electric Power Engineering Department, \\ Faculty of Engineering Technology \\ Al-Balqa' Applied University, As-Salt, Jordan \\ omaralbarbarawi@yahoo.com
}

\begin{abstract}
This study aims to investigate, analyze, discuss and illustrate an effective and reliable fast braking system used in a three-phase induction motor by combining two or more different conventional braking methods such as dynamic-plugging and electromagnetic-plugging. The plugging process is implemented by disconnecting one of the stator phases and connecting it with an electromagnetic brake while interchanging the other two phases. The dynamic process is executed by inserting high resistance in the rotor circuit of the motor. The performance of the torque-speed characteristics of the induction motor will be studied and analyzed through the dynamic process. Mathematical models have been developed and simulated. Results show that the braking process time is greatly reduced.
\end{abstract}

Keywords-electromagnetic brake; plugging-dynamic brake; starting; torque-speed characteristics

\section{INTRODUCTION}

Induction motors (IMs) are commonly used in a wide variety of industrial applications, because of their high robustness, reliability, easy maintenance, low cost, high efficiency and good self-starting [1-12]. The most important control parameters in a motor drive system are starting, speed control and braking processes. Therefore, there is a need to deploy a fast braking system that brings the drive to a standstill after the completion of an operation. Electrical braking for the three-phase IM can be carried out by various methods. These include: regenerative braking, plugging braking, dynamic braking, DC dynamic braking, zero sequence braking etc. [6-8, 9-11]. The braking system technique of an electric motor is basically the removal of the stored kinetic energy from the mechanical part of the system via the speed reduction of the rotating system and the transforming of the stored kinetic energy into another energy which dissipates through heat due to joule effect losses in the rotor bars. This paper presents a new braking method for IMs that integrates two conventional braking methods [6-13] mixing the plugging braking system with the electromagnetic braking system, or with the dynamic braking system. These methods are effective and efficient and employed in many industrial applications. The plugging braking system is achieved by the disconnection of one of the three phases which feed the motor and then connecting it to an electromagnetic braking coil, while, at the same time, the other two supply lines are interchanged. The switching processes are done in proper sequence and the time delays between the successive stages of switching are precise. For proper switching and proper time delay a microcontroller may be used. The plugging process leads to the development of a negative slip that is larger than one and acting on the opposite direction of the torque with respect to the motor rotation [1011]. This new method is effective in a variety of industrial applications for immediate motor stopping. Braking can be achieved by the use of the dynamic braking method by inserting a high resistance in the rotor circuit of the motor, with the plugging braking. The braking methods, namely: electromagnetic-plugging or plugging-dynamic of the 3-phase induction motor have been implemented analytically in a systematic manner. The aim of this contribution is to study and examine new methods of braking for this type of motor drive.

\section{ANALYSIS OF THE ROTATING MAGNETIC FIELD}

In this paper we will study the effect of the magnetic field on the behavior of the motor during braking process, especially when separating one phase from the power supply. Assume the stator of an IM is supplied by equal magnitude three phase currents with phase difference of $120^{\circ}$ between them:

$$
\left.\begin{array}{c}
i_{A A^{\prime}}=I_{m} \sin (\omega t) \\
i_{B B^{\prime}}=I_{m} \sin \left(\omega t-120^{\circ}\right) \\
i_{C C^{\prime}}=I_{m} \sin \left(\omega t-240^{\circ}\right)
\end{array}\right\} A
$$

where $i_{A A^{\prime}}, i_{B B^{\prime}}, i_{C C^{\prime}}$ are the instantaneous stator currents. These currents produce a constant magnitude rotating magnetic field (RMF), which will produce a rotating circular motion that rotates at an angular velocity $\omega[2,4,5]$. The magnitude of the generated magnetic field $\left(B_{\text {net }(t)}\right)$, at any instant of time $(t)$ is:

$$
\begin{aligned}
& B_{\text {net }(t)}=0.5 N_{p h} B_{m}[\sin (\omega t) \dot{x}-\cos (\omega t) \hat{y}]= \\
= & 0.5 N_{p h} B_{m}\left(-\frac{\pi}{2}+\omega t\right), \frac{\omega b}{m^{2}}
\end{aligned}
$$

where $N_{p h}=2,3,4,5 \ldots$, the number of phases. 
This equation is the final expression for the total magnetic flux density $\left(B_{n e t}\right)$ produced in the stator. The magnetic field will have a magnitude equal to $0.5 N_{p h} . B_{m}$. The result of these waves is a sinusoidal wave distributed in the gap of the motor that continues to rotate in a circular motion at an angular velocity $(\omega)$ in clockwise or in counterclockwise direction depending on the phase sequence, and it starts rotating at angle $\angle \pm 90^{\circ}$ as shown in Figure 1. If one of the three phases in the stator of an induction motor is disconnected, the other two phases' currents will produce a magnetic field with variable magnitude. Supposing that a phase of a $\left(\boldsymbol{i}_{A A^{\prime}}\right)$ current from (1) has been disconnected, the other two phases' currents will produce the following magnetic flux density :

$$
\begin{aligned}
& B_{n e t(t)}=B_{B B^{\prime}(t)}+B_{C C^{\prime}(t)}= \\
& 0.5 B_{m} \sin (\omega t)+1.5 B_{m} \cos (\omega t)\left\llcorner \_\pi / 2, \omega b / m^{2}\right.
\end{aligned}
$$

where $B_{A A^{\prime}}, B_{B B^{\prime}}, B_{C C^{\prime}}$ are the instantaneous values of the magnetic field intensities for the different phases. This equation determines the total magnetic flux density presented in the stator, with total value distributed in a sinusoidal wave in the gap. This field begins to rotate in an elliptical form by an angle of $-90^{\circ}$. The outcome of the field is distributed as a sinusoidal wave in the gap of the motor. The field lines are concentrated in a long axis of the phase $\mathrm{AA}^{\prime}$ on the vertices of the elliptic, and we can notice that the field value changes from $0.5 \mathrm{Bm}$ in the middle of the elliptic up to $1.5 \mathrm{Bm}$ on the vertices of the elliptic as shown in Figure 2. Figure 3 shows the results of the simulation aiming to illustrate torque-speed characteristics of a 3-phase IM. In both, motoring and braking regions when one of the three phases in the IM stator is separated from the power supply and a variable external resistance is inserted to the rotor circuit then decrease in motor speed and torque occurs.

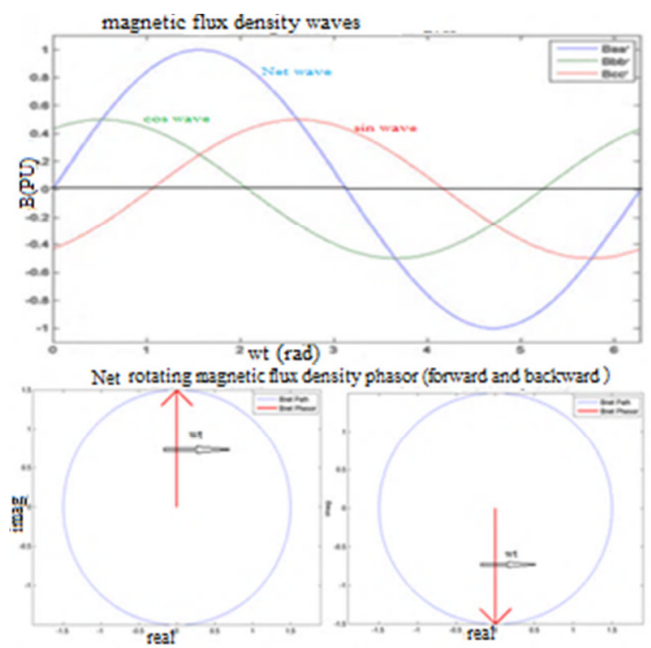

Fig. 1. The sine, cosine and net waves of the magnetic density

\section{BREAKING SYSTEMS}

From the above analysis of the rotating magnetic field, it can be noticed that if any phase is disconnected, the total magnetic flux density presented in the stator, will consist of two parts that are changing in sine and cosine waves as shown in Figure 2. The total value of the flux is distributed in a sinusoidal wave, and it rotates clockwise or counterclockwise in an elliptical form. The total value of the flux density in these cases will vary from $0.5 \mathrm{Bm}$ at middle zone of the ellipse up to $1.5 \mathrm{Bm}$ as shown in Figure 2. The field lines are concentrated on the vertices zone of the ellipse and are weakened in the middle zone of the same ellipse [2-4]. This causes a high magnetic attraction on the vertices (between the stator and rotor), which consequently decreases the speed of the motor. Integrating the two conventional braking systems [5], the electromagnetic braking and plugging braking, is an effective and efficient way to turn off the induction motor causing it to stop. During the braking process of the electromagnetic brake shown in Figure 4, a knife switch as shown in Figure 5 separates one phase from the motor supply and directly connects to the coil of the electromagnetic brake [6-7].

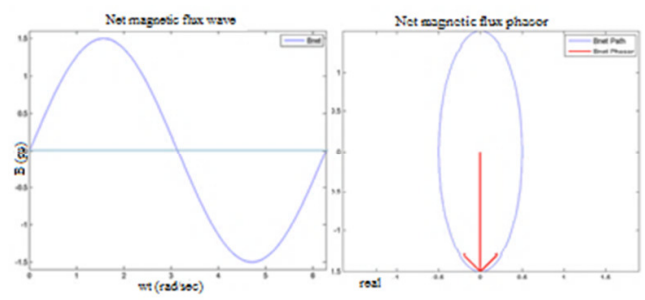

Fig. 2. The net sinusoidal wave field, and space vector of the rotating field when phase current $\boldsymbol{i}_{A A}$ fails

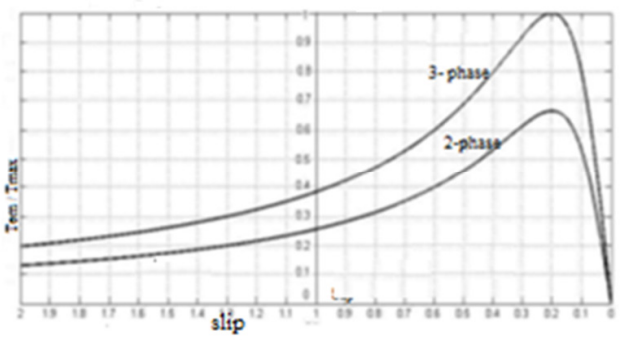

Fig. 3. Torque-speed characteristic for a phase failure, in both motoring and braking

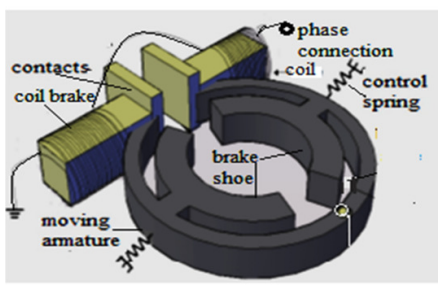

Fig. 4. Electromagnetic brake

While the other two phases have been interchanged using the plugging process, this will energize the coil of the electromagnetic brake which will cause brake shoes to press on the brake drum that is installed on the motor shaft as shown in Figure 5 . The attraction force $\left(F_{a t t}\right)$ between the cores (shoes) of the electromagnetic brake coil can be defined by (4):

$$
F_{a t t}=K_{1} I^{2}-K_{2}
$$

where $K_{l}$ depends on the number of turns of the brake coils, the air gap length, the effective area and the reluctance of the 
armature. $K_{2}$ is the restraining force usually produced by a spring, while $I$ is the rms current of the armature coil.

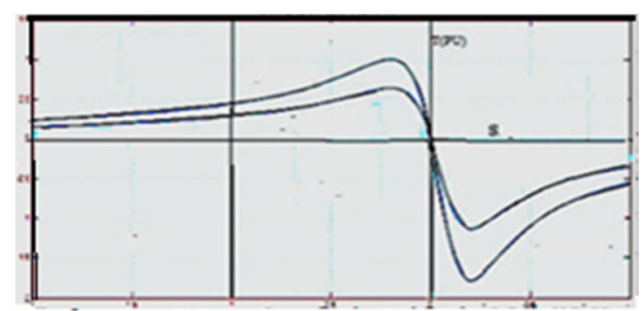

Fig. 5. Torque-speed characteristic for a phase failure, in both motoring, braking and generating

Once one phase of the motor is disconnected from the motor supply, and connected to the electromagnetic brake coils, a strong magnetic attraction will be created between the coil cores (brake shoes). At the same time the plugging brake of the motor will be used by changing the direction of the RMF to oppose the direction of the former magnetic field by interchanging the connections of the other two phase currents of stator with respect to the supply terminals [9]. This leads to a decrease of the maximum torque, by $33.3 \%$ of its original value, as shown in Figure 3 and as a result, the motor decelerates to zero before reversing. The resulting slip during plugging is $(2-S)$, and the original slip of the running motor is $(S)$. Then $(S)$ can be given in the following equation:

$$
S=\frac{-N_{S}-N_{m}}{N_{S}}
$$

where $N_{\mathrm{s}}$ is the synchronous speed and $N_{m}$ the mechanical speed.

As a result the two supply lines are interchanged, the motor speed will decelerate to zero before starting to rotate in the opposite direction, and the braking torque is not zero at zero speed $[8,9]$. A speed sensor can be used to provide a signal to circuit breaker to disconnect the two phases from the power supply when the speed reaches zero. As a result of activating the electromagnetic brake, the motor will stop automatically and immediately in a very short time. Braking process will work automatically with the appropriate arrangement of the switching circuit and a giving appropriate delay time [5]. For the proper switching procedure and proper time delay, a microcontroller can be used so that switching and time delay are easy and reliable. The combined braking system can stop the motor in less than $1 \mathrm{~s}$, safely, without any over voltage, over current or overheating in the motor windings. The illustration of the natural torque-speed characteristic for 3-phase, and 2phase (when one phase is separated from the motor feed), in three regions, motoring, generating and braking is shown in Figure 5. The opposite direction of the torque characteristic and plugging curve are shown in Figure 7, while Figure 6 illustrates the control circuit.

\section{SIMULINK IMPLEMENTATION OF THE INDUCTION MOTOR}

A simple block diagram is simulated to show how to drive an IM and how to use plugging and dynamic braking [10, 11]. The simulation is used to study the effects of variation of the IM's parameters and to determine the behavior of any IM at plugging process. The simulation model is built up systematically by selecting a 3-phase 5hp IM (Table I).

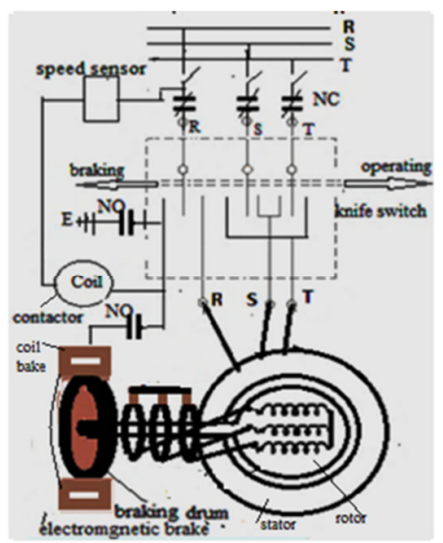

Fig. 6. Control circuit of the electromagnetic-plugging brake

(a)

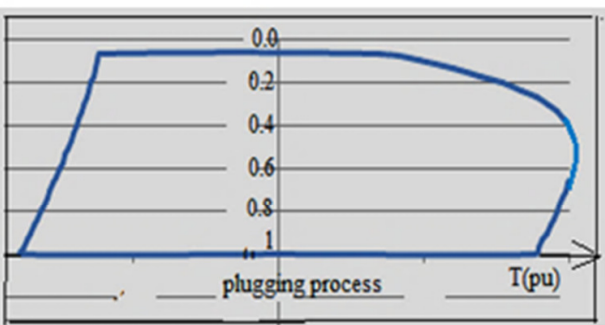

(b)
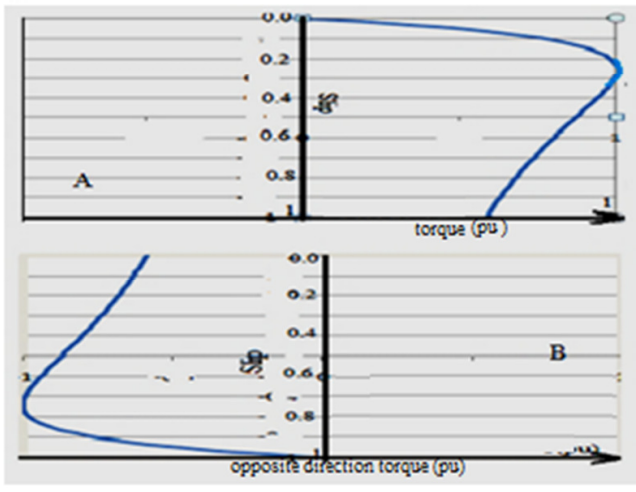

Fig. 7. (a) Natural torque-speed and (b) opposite direction torque-speed characteristics and plugging process

The mathematical model used to calculate and simulate these models has been implemented with the use of Matlab/Simulink. The construction of the basic block diagram and the mathematical model for the plugging and dynamic braking process are based on the ratio between the conventional electromagnetic torque equation $\left(T_{e m}\right)$ and the maximum electromagnetic torque equation $\left(T_{\max }\right)$. Equation (9) is the critical slip equation [5]. The effect of various parameters such as the variation of the rotor resistance and the variable voltage were also used.

$$
T_{e m}= \pm \frac{3 V_{p h}^{2} \times\left(R_{2}^{\prime}+R_{a d}^{\prime}\right)}{S_{F L^{*} W_{S}\left[\left(R_{1}+\left(R_{2}^{\prime}+R_{a d}^{\prime}\right) / S_{F L}\right)^{2}+\left(X_{S C}\right)^{2}\right]}}
$$




$$
\begin{aligned}
& T_{\text {max }}= \pm \frac{3 V_{p h}^{2}}{2 W_{S}\left[ \pm R_{1}+\sqrt{R_{1}^{2}+X_{S C}^{2}}\right]} \\
& \frac{T e m}{T_{\max }}=\frac{2 S_{F L} * S_{C}}{S_{F L}^{2}+S_{C}^{2}}=T^{*}(P U) \\
& S_{C}=\left(R_{2}^{\prime}+R_{a d}^{\prime}\right) / \sqrt{R_{1}^{2}+X_{S C}^{2}}
\end{aligned}
$$

where $V_{p h}$ is the Voltage, $\mathrm{S}_{\mathrm{FL}}, \mathrm{S}_{\mathrm{C}}$ are full load slip and critical slip, $W_{s}$ the angular velocity, $R_{1}, R_{2}^{\prime}$ are the stator and rotor resistances while $X_{S C}=X_{1}+X_{2}^{\prime}$ are the stator and rotor

\begin{tabular}{|c|c|}
\hline P-Power (Watt) & $5 \times 746$ \\
\hline Voltage (V) & 380 \\
\hline Frequency $(\mathrm{Hz})$ & 50 \\
\hline$R_{1}$-Stator resistance $(\Omega)$ & 1115 \\
\hline$L_{1 s}$-Stator inductance $(\mathrm{H})$ & 0.005974 \\
\hline$R_{2}$-Rotor resistance $(\Omega)$ & 1083 \\
\hline$L_{2 r}$-Rotor inductance $(\mathrm{H})$ & 0.005974 \\
\hline$L_{m}$-Mutual inductance (H) & 0.2037 \\
\hline Inertia, friction factor $(\mathrm{kg})$ & $0.02-0.005752$ \\
\hline Pole pairs & 2 \\
\hline
\end{tabular}
inductances. $R_{a d}^{\prime}$ is the external resistance.

TABLE I. 3-PHASE INDUCTION MOTOR PARAMETERS

\section{PlugGing-ELECRTOMAGNETIC BRAKING SIMULATION}

Equations (6)-(9) were simulated in Matlab/Simulink. Figure 8 shows the block diagram model used to implement how the three phase IM can be driven at normal operation and the simulation of the normal plugging and plugging brake.

(a)

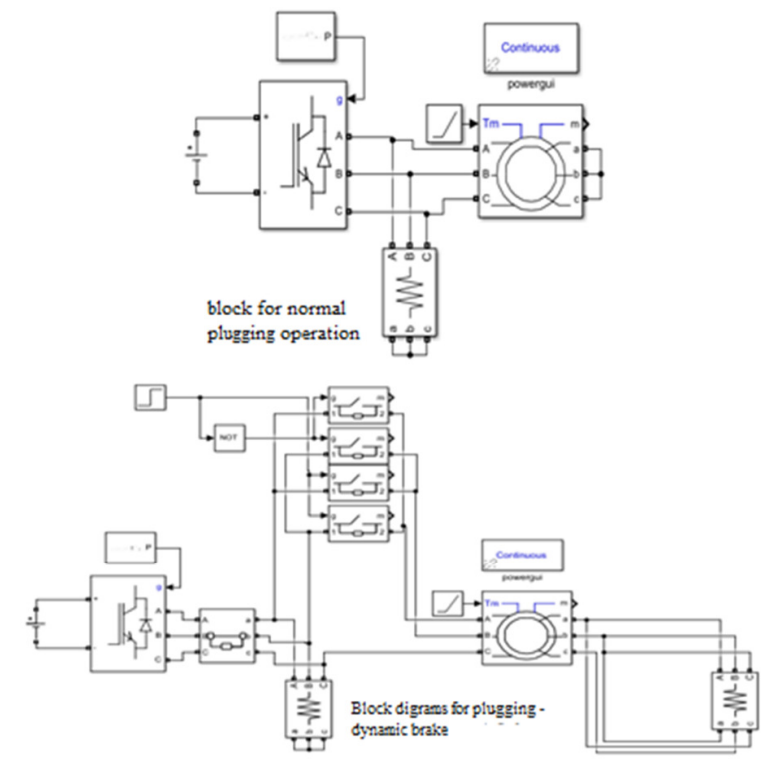

Fig. 8. Block diagrams of (a) normal operation and (b) plugging dynamic braking process

Figures 9-11 show the obtained results of the dynamic behavior of the motor, the oscillating torques as a function of speed, the oscillatory stator currents as a function of time during startup at normal operation and normal plugging with load, without brakes, without phase failure, and its effect upon the speed as a function of time and voltage. (a)

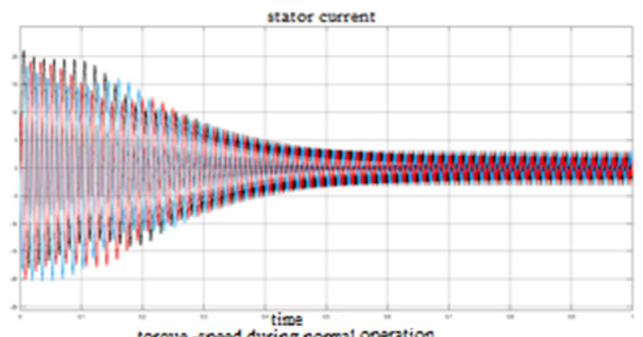

(b)

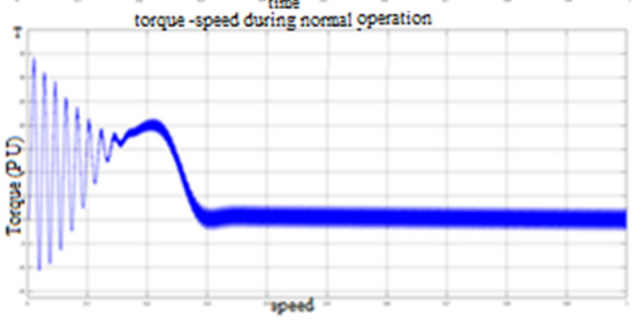

(c)

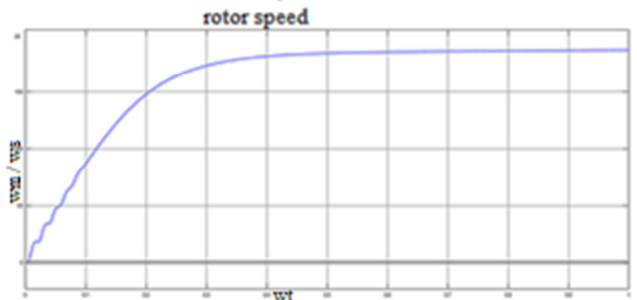

Fig. 9. Simulation results during normal operation, and its effect upon current, torque and speed.

(a)

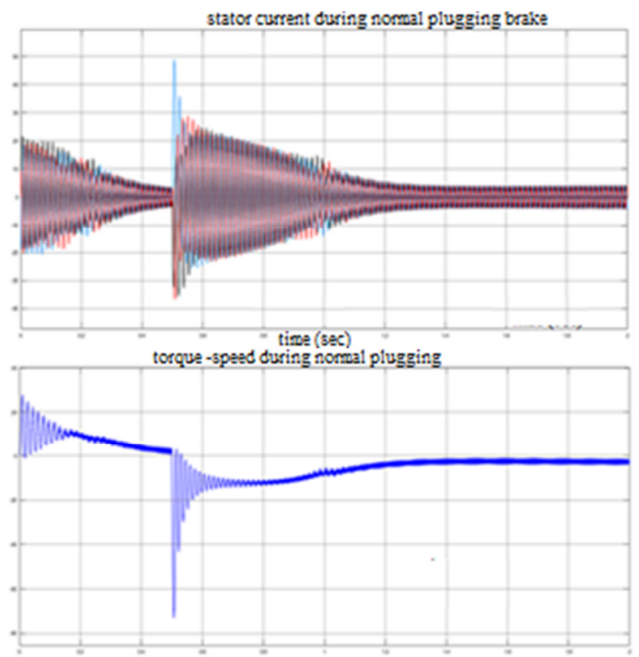

Fig. 10. Simulation results during normal plugging operation, and its effects upon current and torque

Figures 12 and 13 show the results of the stopping process of the motor by using plugging brake, in Matlab/Simulink. The source will be disconnected when the speed reaches zero to satisfy the plugging braking. It is needed to set the breaker parameters on the stator side, to activate the braking when the speed reaches zero by using a speed sensor to provide a signal to the breaker to automatically and immediately stop it.

\section{DYNAMIC-PLUGGING BRAKING}

The moment that one of the three phases is separated, the plugging brake and dynamic brake of the motor are used 
instantly while the separate phase is connected to the contactor coil in the control circuit in order to insert high resistance with the rotor circuit as shown in Figure 1.

(a)

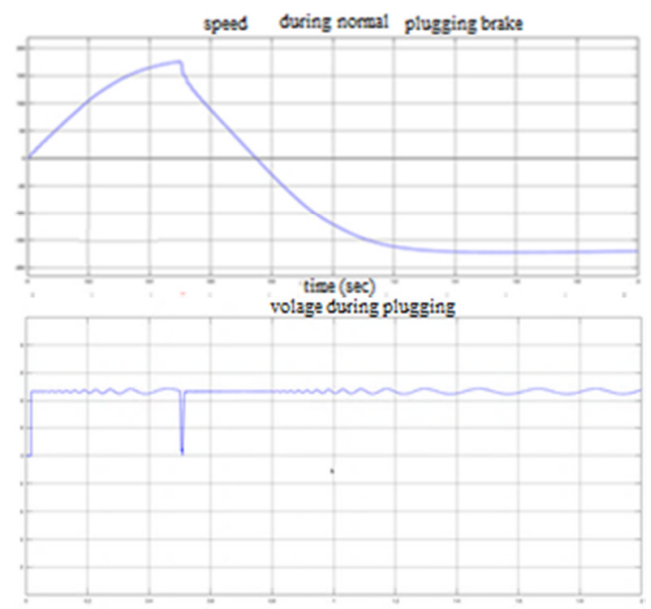

Fig. 11. The simulation results during the plugging operation, and its effects upon speed and voltage

(a)

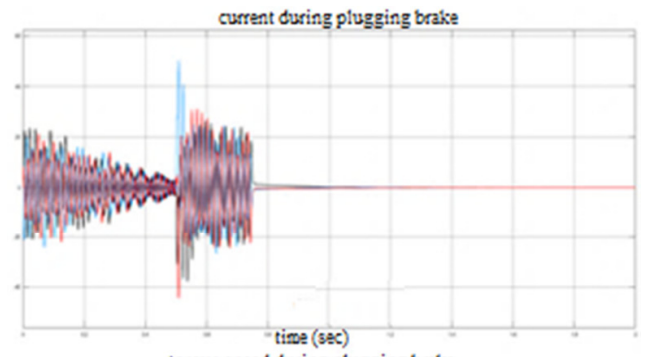

(b)

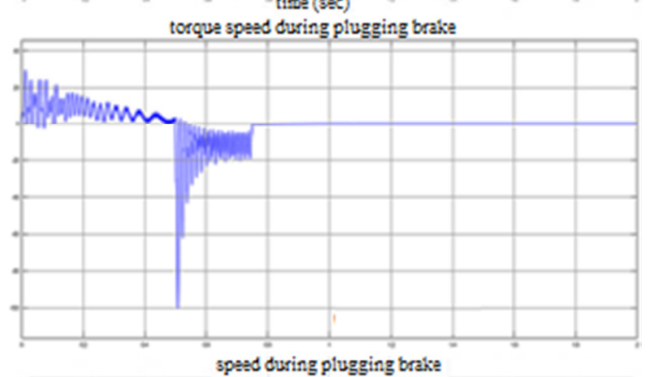

(c)

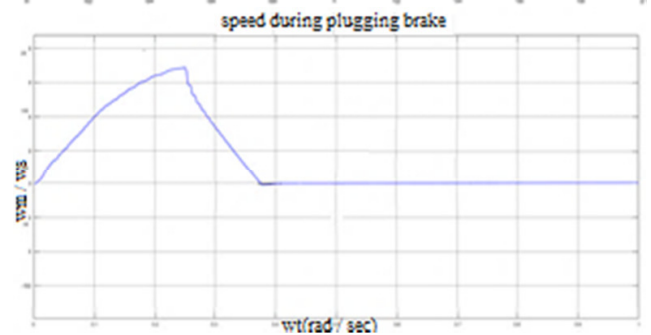

Fig. 12. Simulation results during plugging brake, and its effects upon current, torque and speed

Dynamic braking which has been integrated with the plugging brakes is a process in which the kinetic energy of the rotor is dissipated in the internal and external resistor as heat energy after the main supply separation [9-13]. Dynamic braking process is implemented when the motor operates at the other two phases, which makes the motor act as a single phase motor supplied in the opposite direction as a result of the plugging process, which leads to reduction of the braking torque. In this case, the motor operation as shown in Figure 6. The resistance inserted in the rotor circuit to decelerate the motor speed can be obtained by (10):

$$
R_{\text {Brake }}=\sqrt{R_{1}^{2}+\left(X_{1}-X_{2}^{\prime}\right)^{2}}-R_{2}^{\prime}
$$

Figure 14 illustrates the control circuit diagram of the plugging and dynamic braking process.

(a)

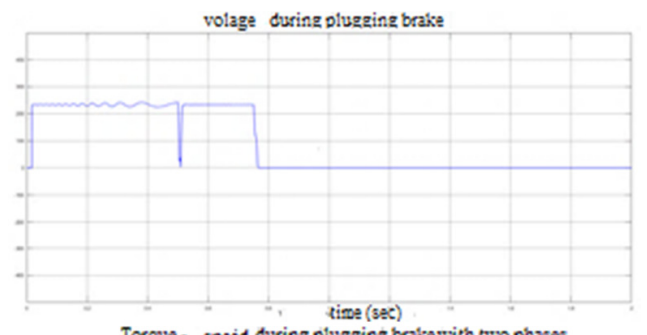

(b)

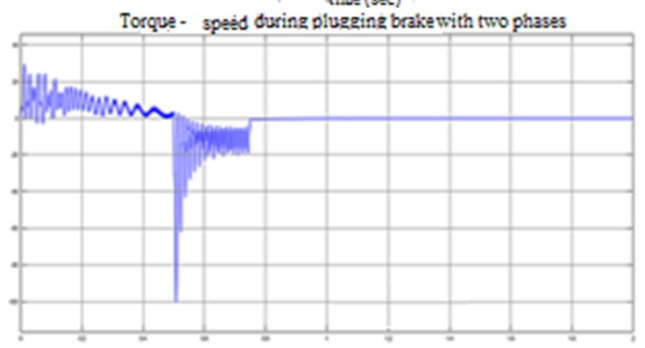

Fig. 13. Simulation results during plugging brake, and its effects upon voltage and torque when one phase fails

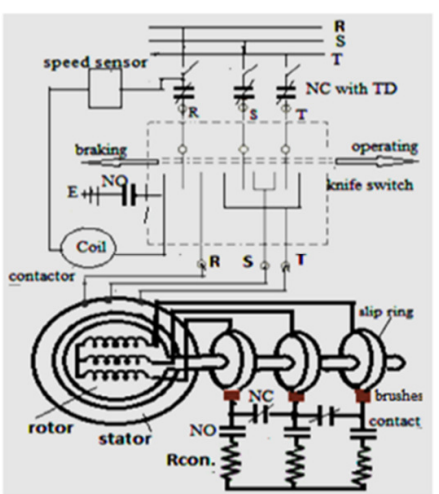

Fig. 14. Control circuit of the dynamic-plugging braking with external resistances

As a result of the single phase separation from the motor feed, this leads to maximum torque reduction. When the plugging brake is used, the magnetic field from the other two phases' currents rotates in an elliptical form on the opposite direction. As a result of the plugging and the dynamic process, inserting a high external resistance in the rotor circuit makes the critical slip increase to one. At this case the speed of the motor decreases to reach zero, while the torque is not zero at zero speed. Near zero speed, we can use a speed sensor to provide a signal to the breaker to automatically operate with the appropriate arrangement of the switching circuit and a giving appropriate delay time by using the microcontroller switch. The 
combined braking system can stop the motor very quickly (in less than 1s) and safely.

\section{SIMULATION OF THE DYNAMIC BRAKING}

A Matlab/Simulik implementation approach similar to the model discussed above has been used to model the dynamicplugging braking for the induction motor by using (6)-(9). Figure 15 shows the block diagram model used to implement and simulate the motor drive and the dynamic-plugging brake using Matlab/Simulink for a three phase IM, to illustrate the performance dynamic- plugging brake on the braking process of the motor at load, when inserting an external resistance in the rotor circuit, with and without disconnection of any phase from the motor feed.

(a)

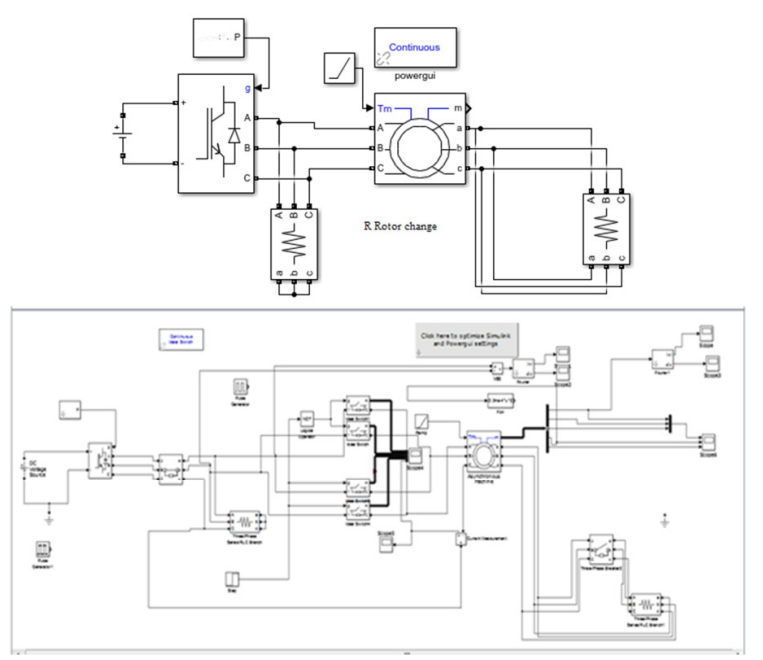

Fig. 15. Block diagrams of the IM model

As highlighted above, when one of the three phases is disconnected from the motor feed and simultaneously a resistance is added to the rotor circuit, as a result the motor speed decelerates to zero. At this instant, a speed sensor is activated and provides a signal to breaker to stop the motor automatically and to disconnect all current phases. Figure 16 shows the Matlab/Simulink simulation results regarding oscillatory currents during start-up at normal operation, at load and at dynamic-plugging brake with and without added resistance.

Figure 17 shows the Matlab/Simulink simulation results regarding the effects of the dynamic-plugging brake on the braking process of the motor during start-up at normal operation at load and at dynamic plugging braking process, when inserting external resistance in the rotor circuit, with and without disconnection of a phase.

Another advantage of the added external resistances is that it decreases the high oscillatory currents in starting and braking process. The mathematical model used is described by (6) and (7) or (8) and (9). Figure 18 shows the effect of inserting variable external resistance in the rotor circuit, on the torquespeed characteristics, in motoring and braking regions. (a)

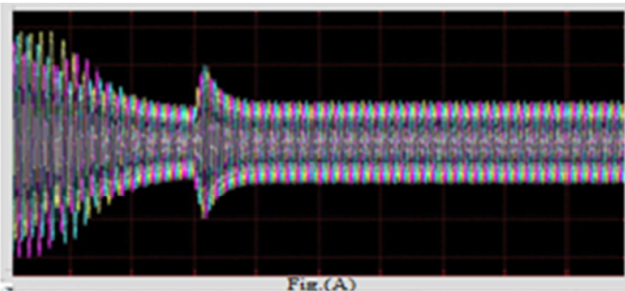

(b)

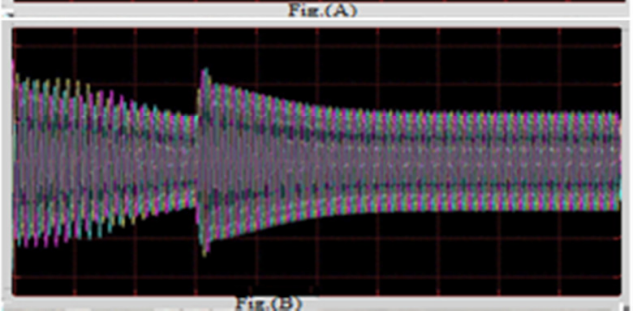

Fig. 16. Simulation results of the oscillatory currents with and without added external resistance

(a)
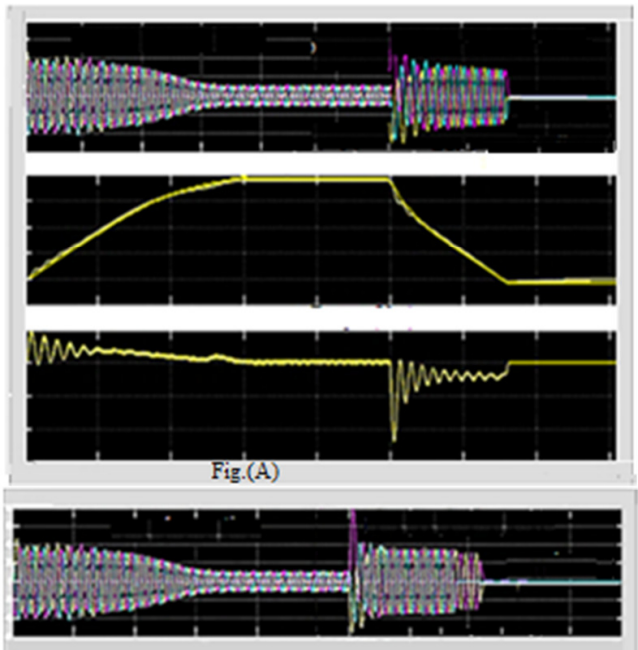

(b)

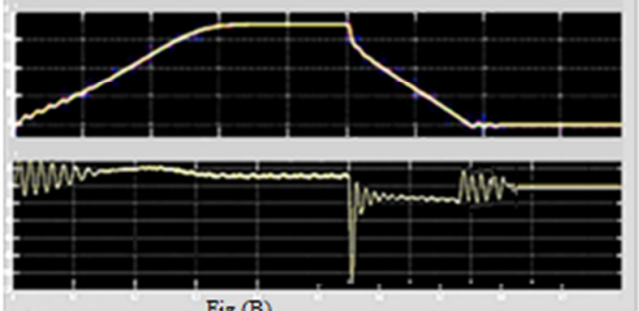

Fig. 17. Simulation results of the oscillatory currents with and without added external resistance

\section{CONCLUSIONS}

Experimental and analytic results show that a most reliable induction motor fast braking system can be designed through the integration of two or more different traditional braking methods with utilization of all their properties. We can use a microcontroller switch to provide suitable arrangements of the switching circuit and to give appropriate time delay between stages, which makes the braking system stop safely and quickly. This paper shows the experimental and analytic results done by the integration of two pairs of conventional braking techniques, plugging brake with electromagnetic brake, and 
plugging brake with dynamic brake. Plugging-electromagnetic brake can be done by disconnecting any phase from the power supply, and connecting it with an electromagnetic brake which will press on the brake disk of the motor.

(a)

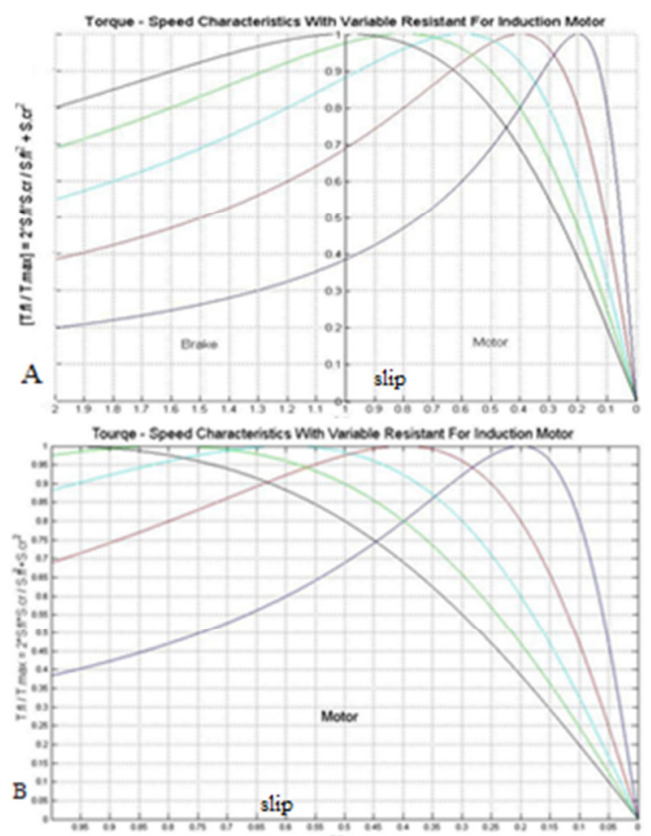

Fig. 18. Programming results illustrating the effect of the added external resistance on the torque-speed characteristics, in both regions

At the same time the connections of the other two phase currents of the stator will interchange with respect to supply terminals (plugging brake). The plugging braking will develop braking torque in the opposite direction of the rotating motor, which leads to deceleration to zero, while the braking torque is not zero at zero speed. The speed sensor provides a signal to circuit breaker to disconnect the two phases from the power supply, to make the motor stop automatically and in very short time. After that all the phases will disconnect from the voltage source before the motor starts to rotate in the reverse direction. This braking method provides simple and fast braking action but with high braking current and losses during the plugging process.

Dynamic-plugging braking is done by disconnecting one phase from the power supply, and connecting it with a control circuit that energizes the contactor coil which inserts an external resistance in the rotor circuit. This procedure leads to increase the braking torque to maximum and the critical slip to reach one, which leads to motor speed deceleration to zero. The plugging brake procedure is done as above. As a result of inserting a resistance in the rotor circuit, the plugging process becomes very slow, which activates the speed sensor to provide a signal to circuit breaker to disconnect the two phases from the power supply in order to stop the motor automatically and immediately. Then, all the phases which feed the motor are disconnected.
The presented braking methods are improving the power factor by reducing braking current and losses. These methods are quicker, more effective and efficient than the conventional ones. In the same reasoning, we also can implement a braking system by integrating three conventional braking systems, plugging braking, dynamic braking and electromagnetic braking, which also is effective and efficient.

\section{REFERENCES}

[1] M. S. Alshamasin, "Control of Zero Sequence Braking for a Three-phase Induction Motor Operating from Single-phase Supply with a Controlled Capacitor", Journal of Applied Sciences, Vol. 12, No. 24, pp. 26162620, 2012

[2] O. M. Al-Barbarawi, "Enhancing the Braking Process, Starting and Electromagnetic Torques of the Induction Motor", International Journal on Engineering Applications, Vol. 5,No. 4, pp. 108-114, 2017

[3] O. M. Al-Barbarawi, "Analysis of the Rotating Magnetic Field of an AC Machines in the Transient Cases”, MAGNT Research, Vol. 4, No. 2, pp. 91-98, 2017

[4] S. J. Chapman Electric Machinery Fundamentals, McGraw-Hill Inc, Avenue of the Americas, New York, 2005

[5] J. Hindmarsh, A. Renfrew, Electrical Machines and Drive Systems, Alasdair Renfrew, 1997

[6] P. L. Rongmei, S. L. Shimi, S. Chatterji, V. K. Sharma, "A Novel Fast Braking System for Induction Motor", International Journal of Engineering and Innovative Technology, Vol. 1, No. 6, pp. 65-69, 2012

[7] D. Sarkar, P. K. Mukherjee, S. K. Sen, "Temperature rise of an induction motor during plugging", IEEE Transactions on Energy Conversion, Vol. 7, No. 1, pp. 116-124, 1992

[8] Y. Yasa, E. Sincar, B. T. Ertugrul, E. Mese, "Design Considerations of Electromagnetic Brakes for Servo Applications", 2014 IEEE 23rd International Symposium on Industrial Electronics, Istanbul, Turkey June 1-4, 2014

[9] C. B. Rajanathan, Z. W. Shi, D. S. Thompson, "Electromechanical Transients in a Three-phase Induction Motor during Phase Failure and Plugging", IEEE Transactions on Magnets, Vol. 33, No. 2, pp. 12191222, 1997

[10] H. A. Hairik, R. H. Thejel, W. A. Kadhem, "Proposed Scheme for Plugging Three-Phase Induction Motor", 15th IEEE Mediterranean Electrotechnical Conference, Valletta, Malta, April 26-28, 2010

[11] M. Covino, M. L. Grassi, E. Pagano, "Analysis of braking Operations in Present-Day Electric Drives with Asynchronous Motors", IEEE International Electric Machines and Drives Conference Record, Milwaukee, USA, May 18-21, 1997

[12] R. Singh, S. Umashankar, D. Vijaykumar, D. P. Kothari, "Dynamic braking of induction motor - Analysis of conventional methods and an efficient multistage braking model", 2013 International Conference on Energy Efficient Technologies for Sustainability, Nagercoil, India, April 10-12, 2013

[13] T. Sukmadi, S. C. Buana, T. Andromeda, M. Facta, "A prototype of multistage dynamic braking of three phase squirrel cage induction motor", 2016 3rd International Conference on Information Technology Computer and Electrical Engineering, Semarang, Indonesia, October 1920,2016 